\title{
Relationships among the Performances of Naming, Discourse Production and IADL in Amnestic MCI
}

\author{
Hyunjoo Choi \\ Department of Communication Disorders, Korea Nazarene University, Cheonan, Korea
}

Correspondence: Hyunjoo Choi, $\mathrm{PhD}$ Department of Communication Disorders, Korea Nazarene University, 48 Wolbong-ro, Seobuk-gu, Cheonan 31172, Korea

Tel: $+82-41-570-1677$

Fax: +82-41-570-7846

E-mail: hjchoi@kornu.ac.kr

Received: July 5, 2019

Revised: August 22, 2019

Accepted: August 22, 2019

This work was supported by the Ministry of Education of the Republic of Korea and the National Research Foundation of Korea (No. NRF2017S1A5A2A01024530)

\begin{abstract}
Objectives: The limitations of the Instrumental Ability of Daily Living (IADL) are known to appear not only in patients with dementia of Alzheimer's type, but also in patients with amnestic mild cognitive impairment (aMCl). The purpose of this study was to investigate the relationship between IADL and the ability of naming and discourse production in patients with aMCl. Methods: Fifty patients with aMCl participated in this study. The naming tests included confrontational naming (Korean version of Boston Naming Test [K-BNT]) and verbal fluency (semantics \& phonemics). Discourse samples were collected from picture description tasks. IADL was assessed using the Korean version Lawton IADL test. Results: First, performances of IADL in patients with aMCl were not significantly correlated with age and education level. However, there was a significant correlation between the Korean version of the Mini-Mental Examination (K-MMSE) score and IADL. Second, performances of IADL in patients with aMCl were not significantly correlated with the performances of the K-BNT and phonemic fluency task. However, the performance of the semantic fluency task and correct information unit (CIU) ratio showed a significant correlation with IADL in patients with aMCl. Third, regression analysis revealed that the performance of the semantic fluency task and the CIU ratio affected the IALD of patients with aMCl. Conclusion: These results suggest that there is a relationship between performances of semantic fluency, discourse production and IADL in patients with $\mathrm{aMCl}$.
\end{abstract}

Keywords: aMCl, Confrontational naming, Verbal fluency, Discourse production, IADL
급속한 인구의 고령화로 인해 노인의 치매 유병률은 증가 추세에 있다. 이러한 치매 환자의 급증으로 정상적인 인지능력과 치매의 중 간 단계, 혹은 치매의 전 단계로 알려진 경도인지장애(mild cognitive impairment, $\mathrm{MCI}$ )에 대한 관심 또한 증대되고 있다. 보건복지 부(2009)에 따르면, 2008년 우리나라의 MCI 유병률은 24.42\%로 추정되어, 65 세 이상 노인 인구의 $1 / 4$ 정도가 $\mathrm{MCI}$ 상태인 것으로 나타났다. 같은 연령 노인들의 치매 유병률이 6.3\%-13\% (Korea Ministry for Health and Welfare, 2013)인 것을 감안하면 MCI 유 병률은 매우 높은 것으로 생각할 수 있다. 또한, 정상 노인이 1년에 $1 \%-2 \%$ 정도 치매로 전이되는 것에 반해 $\mathrm{MCI}$ 환자는 1 년 안에 $12 \%$ 가 치매로 전이되며(Petersen, 2003), MCI 환자의 $80 \%$ 정도가 6년 안에 치매로 발전한다고 알려져 있어(Petersen, 2004), 치매의 조기 발견 및 예방적 측면에서 $\mathrm{MCI}$ 의 중요성이 더욱 부각되고 있다.
$\mathrm{MCI}$ 의 가장 일반적인 진단기준은 (1) 주관적인 기억 장애의 호소, (2) 일상생활 수행능력(activities of daily living, ADL)의 보존, (3) 정상적인 전반적 인지능력의 보유, (4) 객관적 기억력의 저하, (5) 치 매의 진단기준에 충족하지 않음이다(Petersen et al., 1999). 이러한 $\mathrm{MCI}$ 는 이질적인 집단으로 손상영역에 따라 기억 손상이 주증상 인 기억상실형 $\mathrm{MCI}$ (amnestic $\mathrm{MCI}, \mathrm{aMCI}$ )와 기억 이외의 다른 인 지기능 손상이 더 두드러지는 비기억상실형 MCI (non-amnestic $\mathrm{MCI}, \mathrm{naMCI}$ 로 분류할 수 있다(Petersen et al., 2001). 다시, aMCI 는 기억 손상만을 가진 단일영역(single domain) aMCI와 기억 이 외에 하나 이상의 다른 인지기능 손상을 함께 가진 다발영역(multiple domains) aMCI로, naMCI 역시 하나의 인지기능에만 손상을 가진 단일영역(single domain) naMCI와 둘 이상의 인지기능에 손 상을 보이는 다발영역(multiple domains) naMCI로 분류된다(Pe- 
tersen, 2004). 또한, MCI는 유형에 따라 $\mathrm{aMCI}$ 는 알츠하이머형 치 매(dementia of Alzheimer's type, DAT)로 발전될 확률이 높으며, $\mathrm{naMCI}$ 는 DAT 이외의 다른 치매가 될 확률이 높은 것으로 알려져 있다(Busse, Hensel, Gühne, Angermeyer, \& Riedel-Heller, 2006).

$\mathrm{MCI}$ 진단기준에서 중요한 이슈 중 하나는 $\mathrm{ADL}$ 과 관련된 것이 다. $\mathrm{ADL}$ 은 일반적으로 목욕하기, 옷 입기나 식사하기와 같이 신변 처리 및 자기관리기술(self-maintenance skills)을 의미하는 기본적 인 $\mathrm{ADL}$ (basic $\mathrm{ADL}, \mathrm{BADL}$ )과 대중교통 이용하기, 금전 관리, 물건 사기 등과 같이 보다 복잡한 활동으로 구성된 도구적 $\mathrm{ADL}$ (instrumental ADL, IADL)로 나눌 수 있다(Lawton \& Brody, 1969). IADL 은 BADL보다 복잡한 신경심리학적 능력을 요구하기 때문에 미세 한 인지기능의 손상으로도 변화가 나타난다. 따라서 아직 치매로 발병하지 않은 MCI 환자에게서 IADL의 손상이 나타날 수 있으며, 치매 환자를 위한 $\mathrm{IADL}$ 검사로 정상 고령자와 $\mathrm{MCI}$ 환자를 민감하 게 변별해 낼 수 있다고 알려져 있다(Binegar, Hynan, Lacritz, Weine, \& Cullum, 2009). 실제로 여러 연구에서 MCI 환자의 IADL 손 상이 보고되고 있으며, 이와 관련된 Jekel 등(2015)의 문헌연구에 따 르면 $\mathrm{MCI}$ 환자의 IADL 능력을 연구한 37 개의 논문 중 35 개의 논 문에서 $\mathrm{MCI}$ 환자의 전반적인 IADL 혹은 일부 IADL의 손상이 보 고되었다. 따라서 $\mathrm{MCI}$ 의 진단기준인 'ADL의 보존'은 $\mathrm{BADL}$ 에 국 한된 개념으로 수정될 필요가 있다. 또한 이와 관련된 연구들에 따 르면 $\mathrm{MCI}$ 의 유형에 따라 IADL 손상 정도에 차이가 나타나는데, $\mathrm{DAT}$ 로 발전할 가능성이 높은 $\mathrm{aMCI}$ 가 $\mathrm{naMCI}$ 에 비해 IADL의 손 상이 더 두드러지는 것으로 알려져 있다(Binegar et al., 2009; Hong, Jung, Kim, Lee, \& Kim, 2008; Jekel et al., 2015). IADL 하부영역 중 에서도 $\mathrm{aMCI}$ 환자는 금전관리 영역의 손상이 가장 두드러지며 (Triebel et al., 2009), 요리하기, 청소하기와 같은 가정 활동보다는 물건 사기, 약 복용하기, 교통수단 이용하기와 같은 활동에서 수행 이 더 제한된다고 알려져 있다(Mariani et al., 2008). 이러한 활동의 제한은 $\mathrm{aMCI}$ 환자의 언어 및 의사소통 능력의 제한과 관련지어 생 각해 볼 수 있다. 물건 사기, 약 복용하기, 금전관리와 같은 활동은 가정 안에서의 활동에 비해 타인과의 상호작용 및 읽기, 쓰기와 같 은 언어능력이 상대적으로 많이 요구되는 활동이다. 따라서 $\mathrm{aMCI}$ 환자가 미세하지만 언어 및 의사소통 능력에 제한을 보인다는 점을 감안한다면, 이들의 IADL 저하는 언어 및 의사소통 능력의 저하와 관련지어 생각할 수 있다.

$\mathrm{aMCI}$ 환자들의 언어 및 의사소통 능력에 관련된 지금까지의 연 구결과는 혼재되어 있으나, 이들의 언어 및 의사소통 능력에 미세한 손상이 나타난다는 연구결과가 다수 보고되고 있다. 특히, $\mathrm{aMCI}$ 환자들의 이름대기 제한(Alom, Llinares, \& Fajardo, 2012; Bein- hoff, Hilbert, Bittner, Grön, \& Riepe, 2005; Guo, Zhou, Zhao, Wang, \& Hong, 2012)과 담화산출 능력의 저하(Choi, 2013; Duong, Giroux, Tardif, \& Ska, 2005; Fleming \& Harris, 2008; Forbes-McKay \& Venneri, 2005)는 여러 연구에서 확인되었다. 이러한 $\mathrm{aMCI}$ 환자 의 언어장애는 주로 언어능력을 포함한 그 밖의 인지기능을 요구 하는 과제에서 확인할 수 있는데, 이름대기 과제 중 특히 범주별 단 어를 산출하는 구어유창성 검사의 경우 $\mathrm{aMCI}$ 환자의 미세한 언어 손상을 상당히 민감하게 검출하는 검사로 알려져 있다(Gainotti, Quaranta, Vita, \& Marra, 2014). 담화과제 역시 기억, 집행기능 등 언어 이외의 인지기능과 밀접한 관련이 있으며, 특히, 정보전달의 효율성과 같은 의미적 측면의 손상이 $\mathrm{aMCI}$ 환자에게서 특징적으 로 나타나는 것으로 알려져 있다(Duong, Whitehead, Hanratty, \& Chertkow, 2006).

$\mathrm{aMCI}$ 환자들의 IADL 제한 및 언어 및 의사소통 장애는 확인되 었으나 IADL과 언어 및 의사소통 손상 특징은 각각의 영역에서만 이루어졌을 뿐 이들 사이의 관련성에 관한 연구는 매우 제한적이 다. 이와 관련하여 이미 $\mathrm{ADL}$ 전반에 손상이 나타나는 치매 환자의 경우 $\mathrm{ADL}$ 과 언어 및 인지기능장애 사이의 상관 연구가 일부 존재 하는데, 우선 Hall, Vo, Johnson, Barber와 O'Bryant (2011)는 초기 의 DAT 환자일지라도 주의력, 기억 및 학습능력, 집행기능 및 언어 능력의 제한은 ADL에 영향을 미치며, 특히 이름대기 능력은 IADL 저하에 영향을 미친다고 보고하였다. 다음으로 Small, Geldart와 Gutman (2000)은 DAT 환자의 IADL과 의사소통 능력 사이의 관 련성을 보호자 설문을 통하여 알아보았다. 그 결과, 특히 대화, 전화 사용, 물건 관리 등의 IADL 영역은 의사소통 문제와 서로 관련이 있는 것으로 나타났다. 이와 같이 DAT 환자의 IADL과 의사소통 능력 사이의 연구들은 일관된 결과를 보고하고 있으나, 이들 연구 는 방법론적으로 한계를 가진다. 우선 Hall 등(2011)의 연구에서는 언어능력을 평가하기 위하여 Boston Naming Test (BNT)와 통제 단어 연상 검사(Controlled Oral Word Association Test, COWAT; Kang, Chin, Na, Lee, \& Park, 2000)와 같은 이름대기 검사만을 사 용하였다. 그러나 이름대기 과제는 DAT 환자들의 기능적인 언어능 력을 정확히 반영한다고 보기 어렵다. 특히, 다양한 인지기능을 요 구하는 IADL과의 관련성을 살펴보기 위해서는 이름대기 과제보 다는 보다 통합적인 언어능력을 평가할 수 있는 담화 과제(Chapman et al., 2002)를 사용하는 것이 바람직하다. 담화는 언어, 인지, 사회적 상호작용 능력을 반영하는 통합적 의사소통의 단위(Coelho, Liles, \& Duffy, 1990)로 언어능력뿐 아니라 다양한 인지기능을 필요로 하기 때문에(Kwon, Kim, Choi, Na, \& Lee, 1998) IADL과 의 관련성을 살펴보기 위한 언어 과제로 적절하다고 할 수 있다. 다 
음으로 Small 등(2000)의 연구에서는 치매 환자의 의사소통 능력 을 직접적으로 평가한 것이 아닌 보호자의 보고에 의한 간접적인 방법으로 평가하였기 때문에 치매 환자의 실제적인 언어 및 의사소 통 능력을 반영한 결과라고 보기 어렵다.

실제로 $\mathrm{IADL}$ 은 BADL에 비해 언어 및 의사소통 능력을 포함한 다양한 인지기능을 요구함에도 불구하고, $\mathrm{aMCI}$ 환자의 언어능력 제한이 그들의 IADL에 어떠한 영향을 미치는지에 관련된 연구는 이루어지지 않았다. 일부의 연구는 이미 IADL에 현저한 손상을 가 진 치매 환자를 대상으로 하였으며, 과제 역시 이름대기 과제에 국 한되어 있거나 간접적인 방법으로 평가되어 실제적이고 기능적인 의사소통 능력을 반영한다고 보기 어렵다. 일상생활에서의 기능적 의사소통 능력은 $\mathrm{aMCI}$ 환자를 포함한 모든 신경언어장애 환자들 의 가장 중요한 언어치료 목표이며, IADL 은 개인의 독립적인 생활 가능성을 판가름하는 중요한 척도임에도 불구하고 이러한 영역의 관련 연구는 대단히 제한적이다. 따라서 이 연구에서는 DAT로 발전 할 가능성이 높은 $\mathrm{aMCI}$ 환자를 대상으로 연령, 교육년수, K-MM$\mathrm{SE}$ 점수와 $\mathrm{IADL}$ 의 상관을 살펴보고, 이름대기 및 담화산출 능력 과 IADL의 관련성을 알아보는 것을 목적으로 하였다.

\section{연구방법}

\section{연구 대상}

이 연구에서는 $\mathrm{aMCI}$ 환자 50 명(남성 26 명, 여성 24 명)을 대상으 로 하였다. $\mathrm{aMCI}$ 환자는 정신과 전문의에 의해 $\mathrm{aMCI}$ 로 진단받은 환자로, 구체적인 선정기준은 다음과 같다. (1) 환자 본인이나 가족 들에 의한주관적인 기억장애의 호소, (2) 한국판 간이정신상태검사 (Korean-Mini Mental State Examination, K-MMSE; Kang, 2006) 점 수 -1.0 SD 이상으로 일반적 인지기능은 정상 범주에 속함, (3) Barthel Index (Mahoney \& Barthel, 1965) 점수가 20점으로 정상적인 BADL능력을 가짐, (4) Korean version of the Consortium to Establish a Registry for Alzheimer's Disease Assessment Packet (CERAD-K; Lee et al., 2002)의 기억 검사중 하나 이상이 $-1.5 \mathrm{SD}$ 이하로 객관적인 기억력 저하가 확인됨, (5) 치매의 진단기준에 부합하지 않

Table 1. Results of age, education level and K-MMSE score by gender

\begin{tabular}{lrrr}
\hline & \multicolumn{1}{c}{ Male } & \multicolumn{1}{c}{ Female } & \multicolumn{1}{c}{ Total } \\
\hline Age (yr) & $73.31(4.99)$ & $70.33(3.89)$ & $72.36(4.56)$ \\
Education level (yr) & $9.73(4.45)$ & $8.25(2.97)$ & $9.02(3.85)$ \\
K-MMSE & $25.38(1.96)$ & $24.58(2.41)$ & $25.00(2.20)$ \\
\hline
\end{tabular}

Values are presented as mean (SD).

K-MMSE = Korean version of Mini-Mental State Examination (Kang, 2006).
음. 성별에 따른 $\mathrm{aMCI}$ 환자의 연령, 교육년수, $\mathrm{K}-\mathrm{MMSE}$ 점수의 평균 을 Table 1에 제시하였다. 성별에 따라 연령, 교육년수 및 K-MMSE 점수 차이가 유의한지 알아보기 위하여 독립표본 $t$-검정을 실시한 결과 모든 항목에서 성별에 의한차이는 유의하지 않았다 $(p>.05)$.

\section{연구 과제}

$\mathrm{IADL}$ 검사

$\mathrm{aMCI}$ 환자들의 IADL을 평가하기 위해 한국어판 로톤 IADL (Lawton IADL) 지표(Kim, Won, \& Cho, 2005)를 사용하였다. Lawton IADL (Lawton \& Brody, 1969)은 Lawton에 의해 개발된 가장 대표적인 IADL 평가도구로 $\mathrm{aMCI}$ 환자들의 IADL 손상을 정 상 노인으로부터 민감하게 검출해내는 것으로 알려져 있다(Mariani et al., 2008; Pedrosa et al., 2010). 이 연구에서는 aMCI 환자들 의 경우 IADL의 성별에 의한 차이는 없다는 기존의 연구(Perneczky et al., 2006)와 성별에 의한 활동 차이가 나타날 가능성이 높은 가정생활 영역보다는 남녀 모두 수행하는 IADL 영역에서 $\mathrm{MCI}$ 환 자의 수행 제한이 두드러진다는 점(Brown, Devanand, Liu, \& Caccappolo, 2011; Jekel et al., 2015; Mariani et al., 2008; Small et al., 2000)을 고려하여 IADL의 항목 중 남성과 여성 모두에게 평가 가 능한 전화사용 능력(4점), 물건 사기(4점), 교통수단 이용하기(5점), 약 복용하기(3점), 돈 관리 능력(3점)의 5 가지 항목을 평가하였다. 전체 점수는 5점에서 19점이며, 점수가 높을수록 IADL 능력이 제 한됨을 의미한다. 본 연구에서 사용한 한국어판 Lawton IADL 문 항(이하, K-Lawton IADL)의 예시를 Appendix 1에 제시하였다.

\section{이름대기 검사}

$\mathrm{aMCI}$ 환자의 이름대기 능력 중 대면이름대기 능력은 한국판 보 스톤 이름대기 검사(Korean-Boston Naming Test, K-BNT; Kim \& $\mathrm{Na}, 1997)$ 로 평가하였다. 다음으로 구어유창성 검사는 의미적(semantic) 구어유창성과 음운적(phonemic) 구어유창성 과제를 사 용하여 평가하였다. 의미적 구어유창성은 '동물'과 '가게물건'의 두 범주에 해당되는 낱말을 산출하도록 하였으며, 음운적 구어유창성 은 'ㄱ', 'O', ''으로 시작하는 낱말을 산출하도록 하였다. 각 범주 당 1 분 동안 가능한 많은 낱말을 산출하도록 하였으며, 범주 오류, 반복된 낱말, 파생어 등을 제외한 산출 낱말수를 점수로 하였다.

\section{담화산출 과제}

담화산출 과제는 그림을 보고 자발적으로 설명하는 그림설명 과 제(picture description task)를 사용하였다. 이 연구에서는 단일그 림과 연속그림을 모두 사용하며, 단일그림으로 Boston Cookie- 
Theft picture (Goodglass \& Kaplan, 1983)를, 연속그림으로 부부 싸움 그림(Nicholas \& Brookshire, 1993)을 사용하였다. 그림설명 과제의 분석은 기존의 연구를 바탕으로 CIU (correct information unit) 분석방법을 사용하였다. CIU는 주제에 적합하고 정확한 정 보를 제공하는 단어'로 정의되며, 전체 발화에서 CIU가 차지하는 비율인 CIU 비율은 담화산출의 효율성과 정보전달 능력을 평가하 는 것으로 알려져 있다(Kwon et al., 1998; Nicholas \& Brookshire, 1993). 본 연구에서 CIU 비율의 단위는 한국어를 사용하는 aMCI 환자들의 정보전달 능력을 평가하기 위한 다양한 척도 중 민감도 와 특이도가 가장 높은 것으로 알려져 있는 어절을 기준으로 하였 다(Jin, Choi, \& Lee, 2016).

\section{연구 절차}

연구 진행 이전에 나사렛대학교 연구윤리심의위원회(IRB) (No. 17-1019-05)의 심의 및 피험자의 동의를 얻었다. 본 검사는 방해를 최소화한 조용한 장소에서 일대일로 진행하였다. K-Lawton IADL 및 이름대기 과제는 표준화된 실시 절차에 따라 시행하였으며, 담 화산출 과제는 대상자에게 과제에 대해 설명한 후 본 검사를 실시 하였다. 담화산출 과제는 대상자에게 노트북으로 해당 그림을 제 시하고 “이 그림을 잘 보고 저에게 설명해 주세요.”라고 지시하여 반응을 유도하였다. 대상자들의 반응에는 시간 제한을 두지 않았으 며, 기존의 연구(Jin et al., 2016)에 따라 30초 이상의 발화만 분석 대 상으로 하였다. 대상자의 반응은 녹음하고 즉시 전사하였다. CIU

Table 2. K-BNT, verbal fluency, ratio of CIU and IADL in patients with aMCI

\begin{tabular}{lccc}
\hline Task & Male & Female & Total \\
\hline Naming & $40.19(7.31)$ & $39.42(8.20)$ & $39.82(7.68)$ \\
Verbal fluency & & & \\
Semantic & $26.35(8.49)$ & $24.38(6.86)$ & $25.40(7.73)$ \\
$\quad$ Animal & $13.23(4.84)$ & $10.54(3.67)$ & $11.94(4.48)$ \\
$\quad$ Market item & $13.12(4.93)$ & $13.83(4.30)$ & $13.46(4.60)$ \\
Phonemic & $18.58(9.99)$ & $17.67(7.45)$ & $18.14(8.78)$ \\
/k/ (/ ᄀ/) & $6.00(3.84)$ & $5.50(2.75)$ & $5.76(3.34)$ \\
Vowel // /) & $6.46(4.11)$ & $5.83(2.84)$ & $6.16(3.54)$ \\
/s/ / / /) & $6.12(3.46)$ & $6.33(3.27)$ & $6.22(3.33)$ \\
Discourse production & & & \\
CIU (\%) & $63.63(15.52)$ & $63.82(18.49)$ & $63.72(16.84)$ \\
IADL & & & \\
K-Lawton IADL & $6.96(1.00)$ & $7.08(1.93)$ & $7.02(1.50)$ \\
\hline
\end{tabular}

Values are presented as mean (SD).

K-BNT = Korean version of Boston Naming Test (Kim \& Na, 1997); CIU= correct information unit; K-Lawton IADL= Korean Lawton Instrumental Ability Daily Living (Kim, Won, \& Cho, 2005); aMCl = amnestic mild cognitive impairment. ${ }^{*} p<.05$.
비율분석을 위한 어절 및 $\mathrm{CIU}$ 분석에 대한 신뢰도를 평가하기 위 하여 연구자와 1 급 언어재활사 자격증을 소지하고 언어병리학 박 사과정에 재학 중인 제 2 평가자와의 평가자 간 일치도를 산출한 결 과 모두 $90 \%$ 이상으로 나타났다.

\section{통계분석}

모든 통계분석은 IBM SPSS Statistics version 22 프로그램을 이 용하였다. 우선 $\mathrm{aMCI}$ 집단의 성별에 따라 연령, 교육년수 및 KMMSE 점수 차이가 유의한지 알아보기 위하여 독립표본 $t$-검정을 실시하였다. 다음으로 $\mathrm{aMCI}$ 환자의 연령, 교육년수, K-MMSE점수, 이름대기 수행 및 담화산출의 CIU 비율과 IADL 점수의 상관분석 을 실시하였다. 마지막으로, 이름대기 및 CIU비율 중 IADL과 유의 한 상관이 나타난 과제의 수행이 IADL 점수에 미치는 영향을 알아 보기 위하여 중다회귀분석을 실시하였다.

\section{연구결과}

\section{$\mathrm{aMCl}$ 집단의 이름대기 및 담화산출 능력과 IADL 수행}

$\mathrm{aMCI}$ 집단의 K-BNT, 구어유창성, 담화산출 과제에서의 CIU 비 율 및 IADL 점수의 기술통계치를 Table 2에 제시하였다.

$\mathrm{aMCl}$ 집단의 연령, 교육년수, $\mathrm{K}-\mathrm{MMSE}$ 점수와 IADL의 상관 $\mathrm{aMCI}$ 집단의 연령, 교육년수, $\mathrm{K}-\mathrm{MMSE}$ 점수와 $\mathrm{IADL}$ 의 상관을 알아보기 위하여 상관분석을 실시하고, 그 결과를 Table 3에 제시 하였다. aMCI 환자의 K-Lawton IADL 점수는 연령 및 교육년수와 는 유의한 상관이 나타나지 않았으나, K-MMSE 점수와는 유의한 부적상관이 나타났다.

\section{$\mathrm{aMCl}$ 집단의 이름대기 능력과 IADL의 상관}

$\mathrm{aMCI}$ 집단의 이름대기 능력과 IADL의 상관을 알아보기 위하여

Table 3. Correlation among the age, education level, K-MMSE score and Lawton IADL in patients with aMCI

\begin{tabular}{lcccc}
\hline & Age & Education level & K-MMSE & Lawton IADL \\
\hline Age & 1 & - & - & - \\
Education level & .061 & 1 & - & - \\
K-MMSE & -.136 & .072 & 1 & - \\
Lawton IADL & .168 & -.183 & $-.314^{*}$ & 1 \\
\hline
\end{tabular}

K-MMSE = Korean version of Mini-Mental State Examination (Kang, 2006); K-Lawton IADL= Korean Lawton Instrumental Ability Daily Living (Kim, Won, \& Cho, 2005); aMCl= amnestic mild cognitive impairment. ${ }^{*} p<.05$. 
Table 4. Correlation among the performances of K-BNT, verbal fluency, and Lawton IADL in patients with aMCI

\begin{tabular}{|c|c|c|c|c|c|c|c|c|c|}
\hline & \multirow{3}{*}{ K-BNT } & \multicolumn{7}{|c|}{ Verbal fluency } & \multirow{3}{*}{$\begin{array}{c}\text { Lawton } \\
\text { IADL }\end{array}$} \\
\hline & & \multicolumn{3}{|c|}{ Semantic } & \multicolumn{4}{|c|}{ Phonemic } & \\
\hline & & Animal & Market item & Total & $/ \mathrm{k} /$ & vowel & $/ s /$ & Total & \\
\hline K-BNT & 1 & & & & & & & & \\
\hline Animal & .201 & 1 & & & & & & & \\
\hline Market item & $.395^{* *}$ & $.448^{* *}$ & 1 & & & & & & \\
\hline Total of semantics & $.352^{*}$ & $.847^{* *}$ & $.855^{* *}$ & 1 & & & & & \\
\hline$/ k /$ & .212 & $.368^{* *}$ & $.398^{* *}$ & $.450^{* *}$ & 1 & & & & \\
\hline Vowel & .146 & $.312^{*}$ & $.395^{* *}$ & $.416^{* *}$ & $.586^{* *}$ & 1 & & & \\
\hline /s/ & $.292^{*}$ & .143 & $.346^{*}$ & $.298^{*}$ & $.724^{* *}$ & $.528^{* *}$ & 1 & & \\
\hline Total of phonemics & .250 & $.319^{*}$ & $.442^{* *}$ & $.448^{* *}$ & $.891^{* *}$ & $.826^{* *}$ & $.867^{* *}$ & 1 & \\
\hline K-Lawton IADL & -.213 & $-.323^{*}$ & $-.343^{*}$ & $-.392^{*}$ & -.015 & -.189 & -.009 & -.085 & 1 \\
\hline
\end{tabular}

K-BNT = Korean version of Boston Naming Test (Kim \& Na, 1997); K-Lawton IADL= Korean Lawton Instrumental Ability Daily Living (Kim, Won, \& Cho, 2005); aMCl=amnestic mild cognitive impairment.

${ }^{*} p<.05,{ }^{* *} p<.01$.

상관분석을 실시하였다. K-BNT, 구어유창성, K-Lawton IADL 점 수의 상관분석 결과를 Table 4에 제시하였다. 결과를 살펴보면, KLawton IADL 점수는 K-BNT 및 음운적 구어유창성의 수행과는 유의한 상관이 나타나지 않았으나, 의미적 구어유창성의 수행과는 유의한 부적상관을 보였다.

\section{$\mathrm{aMCl}$ 집단의 담화산출 능력과 IADL의 상관}

$\mathrm{aMCI}$ 집단의 담화산출 능력과 $\mathrm{IADL}$ 의 상관을 알아보기 위하여 $\mathrm{CIU}$ 비율과 K-Lawton IADL 점수의 상관분석을 실시한 결과, 상관 계수는 -.312로 유의한 부적상관 $(p<.05)$ 이 있는 것으로 나타났다.

\section{$\mathrm{aMCl}$ 집단의 의미적 구어유창성과 담화산출 능력이 IADL에 미치는 영향}

$\mathrm{aMCI}$ 집단의 $\mathrm{IADL}$ 점수와 유의한 상관을 보인 의미적 구어유 창성 과제 수행과 CIU 비율이 IADL에 미치는 영향을 알아보기 위 하여 중다회귀분석을 실시하였다. 그 결과 의미적 구어유창성과 $\mathrm{CIU}$ 비율을 포함한 회귀선이 모델에 적합한 것으로 나타났으며 $(F=4.955, p<.05)$, 이러한 독립변수가 IADL을 예측하는 설명량은 $17.4 \%$ 로 나타났다. 각 독립변수별 회귀분석에서의 설명량은 의미 적 구어유창성 과제는 $15.3 \%(F=8.703, p<.05)$, CIU 비율은 9.7\% $(F=5.184, p<.05)$ 이었다.

\section{논의 및 결론}

일상생활에서의 기능적 의사소통 능력 향상은 모든 신경언어장 애 환자들의 가장 중요한 언어치료 목표이며, IADL은 개인의 독립
적인 생활 가능성을 판가름하는 중요한 척도이다. 언어 및 의사소 통 능력을 포함한 다양한 인지기능의 손상은 IADL 제한으로 이어 지며, 이는 환자의 독립적인 생활에 어려움을 초래하여 삶의 질을 저하시킬 뿐 아니라 환자 가족 및 보호자의 부담을 가중시킨다 (Sacco et al., 2012). aMCI 환자의 경우 IADL의 제한이 나타난다고 알려져 있지만 IADL과 의사소통 능력 사이의 관계를 살펴본 연구 는 대단히 제한적이다. 따라서 본 연구에서는 DAT로 발전할 가능 성이 높은 $\mathrm{aMCI}$ 환자를 대상으로 연령, 교육년수, $\mathrm{K}-\mathrm{MMSE}$ 점수 와 IADL 점수의 상관을 알아보고, 이름대기 및 담화산출 능력과 IADL 사이의 관련성을 알아보는 것을 목적으로 하였다.

연구결과를 살펴보면 다음과 같다. 첫째, $\mathrm{aMCI}$ 집단의 연령, 교육 년수, K-MMSE 점수와 K-Lawton IADL 점수의 상관분석 결과 $\mathrm{aMCI}$ 환자의 IADL은 연령 및 교육년수와는 유의한 상관이 나타 나지 않았지만, K-MMSE의 점수와 IADL 사이에는 유의한 상관이 나타났다. 이러한 결과는 $\mathrm{MCI}$ 환자의 성별 및 교육년수는 IADL과 유의한 상관이 없었으나, K-MMSE 점수는 IADL과 유의한 상관이 나타났다는 기존의 연구결과(Perneczky et al., 2006)와 일치한다. 이와 관련하여 일부의 연구자들은 다양한 인지기능 평가 과제 중 $\mathrm{MCI}$ 환자들의 IADL 능력을 가장 민감하게 예측하는 척도로 MMSE 점수를 꼽았다(Leckey \& Beatty, 2002; Razani et al., 2007). 즉, $\mathrm{aMCI}$ 환자의 전반적인 인지기능 손상이 그들의 IADL 제한에 가장 많은 영향을 미친다는 것을 알 수 있다. 또한, 기억 및 주의 능 력(Small et al., 2000), 집행기능 (executive function) (Burdick et al., 2005; Hall et al., 2011; Razani et al., 2007)이 IADL과 관련이 있는 것으로 알려져 있다. 이는 $\mathrm{MCI}$ 중에서도 기억장애와 더불어 다른 인지기능 장애를 함께 가지고 있는 다발영역 $\mathrm{aMCI}$ 환자들의 
$\mathrm{IADL}$ 손상이 가장 두드러지며, 이러한 환자들은 IADL 손상으로 인한 치매 진단 가능성이 증가하여 치매 진단 비율이 높아진다는 연구결과(Peres et al., 2006; Perneczky et al., 2006)와 맥락을 같이 한다.

둘째, $\mathrm{aMCI}$ 집단의 이름대기 능력과 $\mathrm{IADL}$ 의 상관분석 결과, $\mathrm{K}-$ Lawton IADL 점수는 K-BNT 및 음운적 구어유창성 과제의 수행 과는 유의한 상관이 나타나지 않았으나, 의미적 구어유창성 과제 의 수행과는 유의한 상관이 나타났다. $\mathrm{MCI}$ 환자의 IADL과 이름대 기 능력의 관련성을 살펴본 연구는 부족하지만, 경도의 DAT 환자 의 ADL과 이름대기 능력을 살펴본 Hall 등(2011)은 경도의 DAT 환자의 경우 $\mathrm{BADL}$ 점수는 이름대기 능력과 상관이 유의하지 않았 으나, $\mathrm{IADL}$ 점수는 K-BNT 및 구어유창성 능력과 유의한 상관이 나타났다고 보고하였다. 이들의 연구결과와 달리 $\mathrm{aMCI}$ 환자를 대 상으로 한 본 연구에서는 K-BNT 점수와 IADL의 상관이 유의하지 않았다.K-BNT와 같은 대면이름대기 과제의 수행은 시각적 대상 인 지 단계, 의미기억을 통한 의미표상 단계, 음운표상의 단계를 거치 는 것으로 알려져 있는데(Abrahams et al., 2003), 본 연구의 결과는 $\mathrm{aMCI}$ 단계에서는 이와 같이 시각적으로 제시된 그림을 보고 이름 을 말하는 과제의 수행은 IADL과는 유의한 관련이 없음을 시사한 다. 대면이름대기 과제에서 $\mathrm{aMCI}$ 환자의 수행 저하와 관련해서는 $\mathrm{aMCI}$ 단계에서는 아직 대면이름대기 능력이 보존된다는 연구결 과와 $\mathrm{aMCI}$ 단계에서 이미 대면이름대기에 문제를 보인다는 연구 결과가 혼재한다(Hwang \& Kim, 2014). 그러나 DAT 진행 과정에 서 대면이름대기 능력의 저하가 나타나도 이러한 과제의 수행은 개 별 환자의 MCI 및 DAT 진단을 위한 척도로 사용하기에는 민감도 가 부족한 것으로 알려져 있다(Testa et al., 2004). 또한, 본 연구에서 는 K-MMSE 점수 평균이 25점 정도에 해당되는 비교적 높은 인지 기능을 가진 $\mathrm{aMCI}$ 환자들을 대상으로 하였기 때문에, 이들의 미 세한 이름대기 능력의 저하를 K-BNT로는 검출하지 못했을 가능 성도 생각해 볼 수 있다. 그럼에도 불구하고 구어유창성 과제 중 의 미적 구어유창성 과제의 수행은 본 연구대상이 된 $\mathrm{aMCI}$ 환자의 $\mathrm{IADL}$ 과 유의한 상관이 있는 것으로 나타났다. 구어유창성 과제는 이름대기 능력과 집행기능을 요구하는 과제로 음운적 구어유창성 과제는 전두엽의 기능을 반영하며, 의미적 구어유창성 과제는 전 두측두엽의 기능을 반영하는 것으로 알려져 있다(Henry \& Crawford, 2004). 따라서 신경병리적으로 측두엽의 두드러진 손상을 가 진 $\mathrm{aMCI}$ 환자의 미세한 의미기억과 관련된 집행기능의 손상을 의 미적 구어유창성 검사가 민감하게 검출하는 것으로 알려져 있다 (Gainotti et al., 2014; Murphy, Rich, \& Troyer, 2006). 앞에서도 언 급했듯이 집행기능은 IADL과 밀접한 관련이 있다(Burdick et al.,
2005; Hall et al., 2011; Razani et al., 2007). Razani 등(2007)은 집행 기능 중에서도 특히 구어유창성(verbal fluency) 과제는 IADL과 강한 상관이 있었다고 보고하였는데, 본 연구결과를 통하여 대면 이름대기와는 달리 의미기억뿐 아니라 집행기능을 요구하는 의미 적 구어유창성 과제 수행과 IADL의 관련이 높음을 확인하였다.

셋째, 상관분석 결과 $\mathrm{aMCI}$ 환자의 CIU 비율은K-Lawton IADL 점수와 유의한 상관이 있는 것으로 나타났다. 이러한 결과는 $\mathrm{aMCI}$ 환자들의 정보전달 능력과 같은 의미적 측면의 의사소통 능력 손 상과 IADL 제한이 관련이 있음을 의미한다. Chapman 등(2002)은 DAT 환자의 기능적 의사소통 능력을 종합적으로 평가하기 위해서 는 담화 과제를 사용하는 것이 바람직하다고 권고하였다. 이러한 담화 과제는 복잡한 인지기능을 요구하는 통합적인 과제로 DAT 환자는 물론 $\mathrm{aMCI}$ 환자의 미세한 의사소통 능력의 제한을 평가하 는 데에도 적절한 것으로 알려져 있다(Choi, 2013; Fleming \& Harris, 2008; Forbes-McKay \& Venneri, 2005). 특히, 본 연구에서 사용 된 $\mathrm{CIU}$ 비율은 한국어 사용자를 대상으로 한 연구에서 $\mathrm{MCI}$ 환자 를 변별하기 위한 담화분석 척도로 민감도와 특이도 측면에서 유 용한 것으로 알려져 있다(Jin et al., 2016). 이와 관련하여 aMCI 환 자의 담화산출 능력과 인지기능 사이의 관련성을 살펴본 기존의 연구결과들은 $\mathrm{aMCI}$ 환자의 담화산출 능력은 의미적 측면의 손상 이 두드러지며, 이름대기, 지연기억 및 작업기억 능력, 집행기능과 유의한 상관이 있다고 보고하였다(Choi, 2015; Choi \& Lee, 2017). 본 연구의 결과는 $\mathrm{aMCI}$ 환자의 언어능력과 기억 및 집행기능의 손상 이 담화산출 과제에 반영되며, 이러한 손상은 IADL의 제한과 관련 이 있음을 시사한다.

마지막으로 IADL과 상관이 나타난 의미적 구어유창성 과제의 수행과 $\mathrm{CIU}$ 비율이 IADL에 미치는 영향을 알아보기 위하여 중다 회귀분석을 실시한 결과, 의미적 구어유창성 과제의 수행과 CIU 비율이 $\mathrm{aMCI}$ 환자의 IADL을 유의하게 예측하는 것으로 나타났 다. 결과를 종합하면, $\mathrm{aMCI}$ 환자의 IADL에 영향을 미치는 것으로 나타난 의미적 구어유창성 과제의 수행과 $\mathrm{CIU}$ 비율은 의미적 측면 의 언어능력과 다양한 인지기능을 요구하는 과제라는 공통점을 가 지며, 따라서 이러한 과제의 수행이 $\mathrm{aMCI}$ 환자의 IADL과 관련이 있음을 알 수 있다.

본 연구에서는 $\mathrm{aMCI}$ 환자의 이름대기 및 담화산출 능력과 IADL 의 관련성을 살펴보고, 구어유창성 과제의 수행과 CIU 비율이 IADL에 미치는 영향을 알아보았다. 관련 연구가 부족한 상황에서 본 연구의 결과는 $\mathrm{aMCI}$ 환자의 의미적 구어유창성과 정보전달 능 력과 같은 언어 및 관련 인지능력의 손상이 IADL의 제한과 관련이 있다는 점을 밝혀낸 점에 의의가 있다. 그러나 본 연구에서는 $\mathrm{aMCI}$ 
환자의 다양한 언어 및 의사소통 능력과 $\mathrm{IADL}$ 사이의 관련성을 살 펴보지 못하고, 이름대기 및 담화산출 능력과 $\mathrm{IADL}$ 의 관련성만을 제한적으로 살펴본 점이 아쉬움으로 남는다. 또한, 본 연구에서 사 용한 K-Lawton IADL 검사는 환자의 일상생활 기능을 확인하고 시간에 따른 변화를 민감하게 평가하는 검사로 알려져 있지만 (Graf, 2009), 자기보고 혹은 면담 방식의 척도 평가로 IADL 평가도 구로서의 한계를 가진다. 최근에는 성과 중심의 IADL 평가 및 비디 오모니터링 시스템을 통한 직접관찰 방식의 IADL 평가 등 환자의 $\mathrm{IADL}$ 을 보다 직접적으로 평가할 수 있는 척도 개발의 필요성이 대 두되고 있다(Sacco et al., 2012; Wadley et al., 2007). 특히, aMCI 환 자와 같이 IADL에 경미한 손상이 예상되는 경우 높은 민감도와 특이도를 가진 평가척도의 개발이 더욱 필요하다. 앞으로는 $\mathrm{aMCI}$ 환자들의 IADL 능력을 보다 정확하게 평가할 수 있는 평가체계가 개발되고, $\mathrm{aMCI}$ 환자들의 다양한 언어 및 의사소통 능력과 IADL 의 관련성을 살펴보는 연구가 진행되기를 바란다.

\section{REFERENCES}

Abrahams, S., Goldstein, L. H., Simmons, A., Brammer, M. J., Williams, S. C., Giampietro, V. P., ... \& Leigh, P. N. (2003). Functional magnetic resonance imaging of verbal fluency and confrontation naming using compressed image acquisition to permit overt responses. Human Brain Mapping, 20(1), $29-40$.

Alom, J., Llinares, I., \& Fajardo, S. (2012). Clinical approach to diagnosis of pre-dementia Alzheimer's disease (CAD-PAD). Dementia and Geriatric Cognitive Disorders Extra, 2(1), 332-342.

Beinhoff, U., Hilbert, V., Bittner, D., Grön, G., \& Riepe, M. W. (2005). Screening for cognitive impairment: a triage for outpatient care. Dementia and Geriatric Cognitive Disorders, 20(5), 278-285.

Binegar, D. L., Hynan, L. S., Lacritz, L. H., Weiner, M. F., \& Cullum, C. M. (2009). Can a direct IADL measure detect deficits in persons with MCI? Current Alzheimer Research, 6(1), 48-51.

Brown, P. J., Devanand, D. P., Liu, X., \& Caccappolo, E. (2011). Functional impairment in elderly patients with mild cognitive impairment and mild Alzheimer disease. Archives of General Psychiatry, 68(6), 617-626.

Burdick, D. J., Rosenblatt, A., Samus, Q. M., Steele, C., Baker, A., Harper, M., ... \& Lyketsos, C. G. (2005). Predictors of functional impairment in residents of assisted-living facilities: the Maryland Assisted Living Study. The Journals of Gerontology Series A: Biological Sciences and Medical Sciences, 60(2), 258-264.
Busse, A., Hensel, A., Gühne, U., Angermeyer, M. C., \& Riedel-Heller, S. G. (2006). Mild cognitive impairment: long-term course of four clinical subtypes. Neurology, 67(12), 2176-2185.

Chapman, S. B., Zientz, J., Weiner, M., Rosenberg, R., Frawley, W., \& Burns, M. H. (2002). Discourse changes in early Alzheimer disease, mild cognitive impairment, and normal aging. Alzheimer Disease \& Associated Disorders, 16(3), 177-186.

Choi, H. (2013). Characteristics of naming and discourse in patients with amnestic mild cognitive impairment. Journal of Speech-Language and Hearing Disorders, 22(1), 17-33.

Choi, H. (2015). Ratio of Correct Information Unit and cognitive functions in healthy elderly adults. Communication Sciences \& Disorders, 20(3), 435445.

Choi, H., \& Lee, J. Y. (2017). Relationship to ratio of correct information unit and cognitive functions in patients with amnestic MCI and EAD. Communication Sciences \& Disorders, 22(3), 550-560.

Coelho, C. A., Liles, B. Z., \& Duffy, R. J. (1990). Contextual influences on narrative discourse in normal young adults. Journal of Psycholinguistic Research, 19(6), 405-420.

Duong, A., Giroux, F., Tardif, A., \& Ska, B. (2005). The heterogeneity of picture-supported narratives in Alzheimer's disease. Brain and Language, 93(2), 173-184.

Duong, A., Whitehead, V., Hanratty, K., \& Chertkow, H. (2006). The nature of lexico-semantic processing deficits in mild cognitive impairment. Neuropsychologia, 44(10), 1928-1935.

Fleming, V. B., \& Harris, J. L. (2008). Complex discourse production in mild cognitive impairment: detecting subtle changes. Aphasiology, 22(7-8), 729740 .

Forbes-McKay, K. E., \& Venneri, A. (2005). Detecting subtle spontaneous language decline in early Alzheimer's disease with a picture description task. Neurological Sciences, 26(4), 243-254.

Gainotti, G., Quaranta, D., Vita, M. G., \& Marra, C. (2014). Neuropsychological predictors of conversion from mild cognitive impairment to Alzheimer's disease. Journal of Alzheimer's Disease, 38(3), 481-495.

Goodglass, H., \& Kaplan, E. (1983). The assessment aphasia and related disorders (2nd ed.). Philadelphia, PA: Lea and Febiger.

Graf, C. (2009). The Lawton instrumental activities of daily living (IADL) scale. The Gerontologist, 9(3), 179-186.

Guo, Q. H., Zhou, B., Zhao, Q. H., Wang, B., \& Hong, Z. (2012). Memory and Executive Screening (MES): a brief cognitive test for detecting mild 
cognitive impairment. BMC Neurology, 12, 119.

Hall, J. R., Vo, H. T., Johnson, L. A., Barber, R. C., \& O’Bryant, S. E. (2011). The link between cognitive measures and ADLs and IADL functioning in mild Alzheimer's: what has gender got to do with it? International Journal of Alzheimer's Disease, 2011, 276734.

Henry, J. D., \& Crawford, J. R. (2004). A meta-analytic review of verbal fluency performance following focal cortical lesions. Neuropsychology, 18(2), 284-295.

Hong, J. H., Jung, H. Y., Kim, Y. R., Lee, S. Y., \& Kim, J. M. (2008). Restriction of instrumental activities of daily living in MCI. Journal of Korean Neuropsychiatric Association, 47(4), 318-324.

Hwang, Y. K., \& Kim, H. (2014). Utility of the Boston Naming test in differentiating between mild cognitive impairment and normal elderly: a metaanalysis. Communication Sciences \& Disorders, 19(4), 501-512.

Jekel, K., Damian, M., Wattmo, C., Hausner, L., Bullock, R., Connelly, P. J., ... \& Kramberger, M. G. (2015). Mild cognitive impairment and deficits in instrumental activities of daily living: a systematic review. Alzheimer's Research \& Therapy, 7, 17.

Jin, C., Choi, H., \& Lee, J. Y. (2016). Usefulness of spontaneous speech analysis scales in patients with mild cognitive impairment and dementia of Alzheimer's type. Communication Sciences \& Disorders, 21(2), 284-294.

Kang, Y. (2006). A normative study of the Korean-Mini Mental State Examination (K-MMSE) in the elderly. Korean Journal of Psychology: General, 25(2), 1-12.

Kang, Y., Chin, J. H., Na, D. L., Lee, J., \& Park, J. S. (2000). A normative study of the Korean version of Controlled Oral Word Association Test (COWAT) in the elderly. Korean Journal of Clinical Psychology, 19(2), 385-392.

Kim, H., \& Na, D. (1997). Korean Boston Naming Test (K-BNT). Seoul: Hakjisa. Kim, S. Y., Won, J. W., \& Cho, K. W. (2005). The validity and reliability of Korean version of Lawton IADL Index. Journal of the Korean Geriatrics Society, 9(1), 23-29.

Korea Ministry for Health and Welfare. (2009). Nationwide study on the prevalence of dementia in Korea elders, 2018. Retrieved from http://www.mohw. go.kr.

Korea Ministry for Health and Welfare. (2013). Nationwide study on the prevalence of dementia in Korea elders 2012. Retrieved from: http://www. mohw.go.kr.

Kwon, M., Kim, H., Choi, S. S., Na, D. L., \& Lee, K. H. (1998). A study for analyzing spontaneous speech of Korean adults with CIU scoring system. Korean Journal of Communication \& Disorders, 3(1), 35-49.
Lawton, M. P., \& Brody, E. M. (1969). Assessment of older people: self-maintaining and instrumental activities of daily living. The Gerontologist, 9(3), 179-186.

Leckey, G. S., \& Beatty, W. W. (2002). Predicting functional performance by patients with Alzheimer's disease using the Problems in Everyday Living (PEDL) Test: a preliminary study. Journal of the International Neuropsychological Society, 8(1), 48-57.

Lee, J. H., Lee, K. U., Lee, D. Y., Kim, K. W., Jhoo, J. H., Kim, J. H., ... \& Woo, J. I. (2002). Development of the Korean version of the Consortium to Establish a Registry for Alzheimer's Disease Assessment Packet (CERAD-K) clinical and neuropsychological assessment batteries. The Journals of Gerontology Series B: Psychological Sciences and Social Sciences, 57(1), P47-P53.

Mahoney, F. I., \& Barthel, D. W. (1965). Functional evaluation: the Barthel Index: a simple index of independence useful in scoring improvement in the rehabilitation of the chronically ill. Maryland State Medical Journal, 14, 61-65.

Mariani, E., Monastero, R., Ercolani, S., Rinaldi, P., Mangialasche, F., Costanzi, E., ... \& Mecocci, P. (2008). Influence of comorbidity and cognitive status on instrumental activities of daily living in amnestic mild cognitive impairment: results from the ReGAl project. International Journal of Geriatric Psychiatry, 23(5), 523-530.

Murphy, K. J., Rich, J. B., \& Troyer, A. K. (2006). Verbal fluency patterns in amnestic mild cognitive impairment are characteristic of Alzheimer's type dementia. Journal of the International Neuropsychological Society, 12(4), 570-574.

Nicholas, L. E., \& Brookshire, R. H. (1993). A system for quantifying the informativeness and efficiency of the connected speech of adults with aphasia. Journal of Speech, Language, and Hearing Research, 36(2), 338-350.

Pedrosa, H., De Sa, A., Guerreiro, M., Maroco, J., Simões, M. R., Galasko, D., \& de Mendonça, A. (2010). Functional evaluation distinguishes MCI patients from healthy elderly people: the ADCS/MCI/ADL scale. The Journal of Nutrition, Health \& Aging, 14(8), 703-709.

Peres, K., Chrysostome, V., Fabrigoule, C., Orgogozo, J. M., Dartigues, J. F., \& Barberger-Gateau, P. (2006). Restriction in complex activities of daily living in MCI: impact on outcome. Neurology, 67(3), 461-466.

Perneczky, R., Pohl, C., Sorg, C., Hartmann, J., Tosic, N., Grimmer, T., ... \& Kurz, A. (2006). Impairment of activities of daily living requiring memory or complex reasoning as part of the MCI syndrome. International Journal of Geriatric Psychiatry, 21(2), 158-162.

Petersen, R. C. (2003). Mild cognitive impairment: aging to Alzheimer's dis- 
ease. New York, NY: Oxford University Press.

Petersen, R. C. (2004). Mild cognitive impairment as a diagnostic entity. Journal of Internal Medicine, 256(3), 183-194.

Petersen, R. C., Doody, R., Kurz, A., Mohs, R. C., Morris, J. C., Rabins, P. V., ... \& Winblad, B. (2001). Current concepts in mild cognitive impairment. Archives of Neurology, 58(12), 1985-1992.

Petersen, R. C., Smith, G. E., Waring, S. C., Ivnik, R. J., Tangalos, E. G., \& Kokmen, E. (1999). Mild cognitive impairment: clinical characterization and outcome. Archives of Neurology, 56(3), 303-308.

Razani, J., Kakos, B., Orieta-Barbalace, C., Wong, J. T., Casas, R., Lu, P., ... \& Josephson, K. (2007). Predicting caregiver burden from daily functional abilities of patients with mild dementia. Journal of the American Geriatrics Society, 55(9), 1415-1420.

Sacco, G., Joumier, V., Darmon, N., Dechamps, A., Derreumaux, A., Lee, J. H., ... \& David, R. (2012). Detection of activities of daily living impairment in Alzheimer's disease and mild cognitive impairment using information and communication technology. Clinical Interventions in Aging, 7, 539-
549.

Small, J. A., Geldart, K., \& Gutman, G. (2000). Communication between individuals with dementia and their caregivers during activities of daily living. American Journal of Alzheimer's Disease, 15(5), 291-302.

Testa, J. A., Ivnik, R. J., Boeve, B., Petersen, R. C., Pankratz, V. S., Knopman, D., ... \& Smith, G. E. (2004). Confrontation naming does not add incremental diagnostic utility in $\mathrm{MCI}$ and Alzheimer's disease. Journal of the International Neuropsychological Society, 10(4), 504-512.

Triebel, K. L., Martin, R., Griffith, H. R., Marceaux, J., Okonkwo, O. C., Harrell, L., ... \& Marson, D. C. (2009). Declining financial capacity in mild cognitive impairment: a 1-year longitudinal study. Neurology, 73(12), 928934.

Wadley, V. G., Crowe, M., Marsiske, M., Cook, S. E., Unverzagt, F. W., Rosenberg, A. L., \& Rexroth, D. (2007). Changes in everyday function in individuals with psychometrically defined mild cognitive impairment in the Advanced Cognitive Training for Independent and Vital Elderly Study. Journal of the American Geriatrics Society, 55(8), 1192-1198. 
Hyunjoo Choi • Naming, Discourse Production and IADL in aMCI

Appendix 1. Examples of Korean Lawton IADL index

\begin{tabular}{lcl}
\hline 항목 & 점수 & \multicolumn{1}{c}{ 내용 } \\
\hline F. 교통수단 이용 & 1 & 대중교통 수단이나 자가용을 운전해서 혼자서 어디든지 간다. \\
& 2 & 택시는 혼자 타고 가지만 다른 대중교통 수단은 이용하지 않는다. \\
& 3 & 다른 사람이 동행하거나 도와주면 대중교통 수단을 이용한다. \\
G. 약 복용하기 & 4 & 다른 사람이 도와주면 택시나 자가용만 이용한다. \\
& 5 & 교통 수단을 이용하지 않는다. \\
& 1 & 제때 정해진 용량의 약을 혼자서 먹는다. \\
& 2 & 약을 준비해 놓으면 혼자서 먹는다. \\
& 3 & 혼자서는 약을 먹을 수 없다. \\
\hline
\end{tabular}




\section{국문초록}

\section{기억상실형 경도인지장애 환자의 이름대기 및 담화산출 능력과 도구적 일상생활 능력의 상관 최현주}

나사렛대학교 언어치료학과

배경 및 목적: 도구적 일상생활 능력(instrumental ability of daily living, IADL)의 제한은 치매 발병 이전 단계인 경도인지장애(mild cognitive impairment, MCI) 환자에게도 나타나는 것으로 알려져 있다. 본 연구에서는 알츠하이머형 치매로 발전할 가능성이 높은 기 억상실형 $\mathrm{MCI}$ (amnestic $\mathrm{MCI}, \mathrm{aMCI}$ ) 환자의 이름대기 및 담화산출 능력과 $\mathrm{IADL}$ 사이의 관련성을 살펴보았다. 방법: 본 연구는 $\mathrm{aMCI}$ 환자 50명을 대상으로 하였다. 이름대기 능력은 대면이름대기(Korean-Boston Naming Test, K-BNT)와 구어유창성 검사(의미, 음운)를 사용하였으며, 담화산출 능력은 그림설명을 통한 CIU (correct information unit) 비율로 측정하였다. IADL은 한국판 Lawton $\mathrm{IADL}$ 검사를 사용하여 평가하였다. 결과: 첫째, $\mathrm{aMCI}$ 환자의 IADL은 연령 및 교육년수와는 유의한 상관이 나타나지 않았으며, 한국 판 간이정신상태검사(Korean version of Mini-Mental Examination) 점수와 IADL 사이에는 유의한 상관이 있었다. 둘째, $\mathrm{aMCI}$ 환자의 IADL은 K-BNT 및 음운적 구어유창성 과제의 수행과는 유의한 상관이 나타나지 않았으나, 의미적 구어유창성 과제의 수행과 CIU 비 율과는 유의한 상관을 보였다. 셋째, 회귀분석 결과 의미적 구어유창성 과제의 수행과 CIU 비율은 $\mathrm{aMCI}$ 환자의 IALD에 영향을 미치 는 것으로 나타났다. 논의 및 결론: 이러한 결과는 $\mathrm{aMCI}$ 환자의 의미적 구어유창성 및 담화산출 능력과 IADL 사이에 관련성이 있음 을 시사한다.

핵심어: 기억상실형 경도인지장애, 대면이름대기, 구어유창성, 담화산출, 도구적 일상생활 능력

본 논문은 2017년 대한민국 교육부와한국연구재단의 지원을 받아수행된 연구임(No. NRF-2017S1A5A2A01024530).

\section{참고문헌}

강연욱(2006). K-MMSE (Korean-Mini Mental State Examination)의 노인 규준 연구. 한국심리학회지: 일반, 25(2), 1-12.

강연욱, 진주희, 나덕렬, 이정희, 박재설(2000). 통제 단어 연상 검사(Controlled Oral Word Association Test)의 노인 규준 연구. 한국심리학회지: 임 상, 19(2), 385-392.

권미선, 김향희, 최상숙, 나덕렬, 이광호(1998). 한국 성인의 자발화 분석에 관한 연구: CIU분석법을 중심으로. 언어청각장애연구, 3(1), 35-49.

김수영, 원장원, 조경환(2005). 한국어판 로톤 도구적 일상활동 지표(Lawton Instrumental Activities of Daily Living Index)의 개발. 노인병, 9(1), 23-

29.

김향희, 나덕렬(1997). 한국판 보스톤 이름대기 검사(K-BNT). 서울: 학지사.

보건복지부(2009). 2008년 치매유병률 조사. http://www.mohw.go.kr

보건복지부(2013). 2012년 전국 치매 역학 조사. http://www.mohw.go.kr.

진천, 최현주, 이준영(2016). 경도인지장애 및 알츠하이머형 치매 환자의 자발화 분석 척도의 유용성. Communication Sciences \& Disorders, 21(2),

284-294.

최현주(2013). 건망형 경도인지장애 환자의 이름대기 및 담화 과제의 수행 특성. 언어치료연구, 22(1), 17-33.

최현주(2015). 일반 노인의 정보 전달 능력과 인지기능과의 상관. Communication Sciences \& Disorders, 20(3), 435-445.

최현주, 이준영(2017). 기억상실형 경도인지장애와 초기 알츠하이머병 환자의 정보전달 능력과 인지기능과의 상관. Communication Sciences \& Dis-

orders, 22(3), 550-560.

홍지혜, 정한용, 김양래, 이소영, 김진만(2008). 경도인지장애 환자에서 복합-일상활동의 제한. 신경정신의학, 47(4), 318-324.

황윤경, 김향희(2014). 경도인지장애 변별을 위한 보스턴 이름대기 검사의 유용성: 메타 분석. Communication Sciences \& Disorders, 19(4), 501-512. 
Hyunjoo Choi • Naming, Discourse Production and IADL in aMCI

\section{ORCID}

최현주(https://orcid.org/0000-0003-4654-3206) 